\title{
Research on Cross - cultural Management in Transnational Management of Enterprises
}

\author{
Weiwei Chen \\ Sichuan University Jincheng College, Chengdu, Sichuan, 611731
}

\begin{abstract}
With the rapid development of the global economy, transnational management has become a necessary way for enterprises to integrate into the global village economy. Due to cultural differences, enterprises must face the opportunities and challenges of cross-cultural management in transnational management. This paper analyzes the intercultural management problems in cross-border management of enterprises and puts forward the countermeasures and suggestions on cross-cultural management.
\end{abstract}

Keywords: cross - cultural management, transnational management, enterprises

\section{Introduction}

As the world economic integration and regional economic group of continuous development, many enterprises will go out of the country and people of different cultural backgrounds and enterprises to deal with more and more Chinese enterprises in order to seize the opportunity in the international market began in the global scope within the transnational operations. This also means that these multinational companies to multinational operation as a platform, and in this platform with different cultural backgrounds of customers, suppliers, partners, employees and government personnel to integrate, so that in the customs and habits of life, value orientation and other aspects of the differences to achieve a balance, so that Chinese enterprises in this platform access to a variety of capital, technology, information, personnel and other resources at the same time, enhance the international market competitiveness. Therefore, in the internationalization process, how to deal with these cultural differences have become the Chinese 
enterprises to solve cultural conflicts and cross-cultural management of the key issues. This requires us to transnational business in the cross-cultural management of different countries and the impact of factors of in-depth study, so that Chinese enterprises in the process of cross-border management to avoid cultural differences and major mistakes, which is truly Chinese enterprises to achieve internationalization of the important premise of protection. Therefore, the study of cross-cultural enterprise management, the theoretical workers, business managers and entrepreneurs have important theoretical significance and practical value, but also Chinese enterprises to implement international business strategy of the best choice.

Under the background of global economic integration, many enterprises have carried out the activities of foreign direct investment and asset acquisition. The management of the enterprise has gone beyond national boundaries and beyond the original cultural boundary. However, most enterprises are in the early stages of international development, to a certain extent, there are different business environment, not suited to the situation. Perspective of cross-border business activities of Chinese enterprises can be found, almost all companies engaged in cross-border cross-regional business activities are invariably encountered the same problem - how to do business cross-cultural management issues. As for the multinational operation of Chinese enterprises, how to solve the problem of cultural differences in different countries and the weak links of cross-cultural management in management has become one of the important obstacles to the multinational operation of Chinese enterprises. As we all know, the cultures of different nationalities are different in objectivity. The customs and habits of different countries and different nations, morals and traditions, material and spiritual pursuits are different. Cultural differences as an important factor on the impact of multinational management can not be underestimated. The difference between the main culture and the subculture of the multinational enterprise, the difference between the Chinese native culture and the host country culture, will lead the international management enterprise to appear the different level contradiction and the deviation in the management level. Therefore, how to realize the "localization" of Chinese enterprises in multinational operation, how to make the multinational enterprises become more important in the creation of brand, innovative products, integration of resources, marketing and so on. In the information network, market-oriented, especially economic globalization, international trade integration, driven by multinational corporations through the integration of reshaping corporate culture, to achieve mutual communication and integration, and thus comprehensively enhance the international competitiveness of Chinese enterprises has also become a Chinese enterprise out of the world's historical mission.

\section{The definition of cross-cultural management}

Cross-culture management (Cross-culture Management), refers to the process of cross-border business, the subsidiary of the host country's culture that is in 
different cultural types, different races, different stages of development culture inclusive and integrated management tools and methods and thus create a management process that reflects the new corporate culture between the host country and the host country or between the host country and the host country. Also refers to the cross-cultural formation and development process. Different countries, nationalities and organizations have different cultures, and crosscultural management is the study of different cultural background management theory and methods. It is the transnational and transnational management of transnational corporations when they operate in other countries. Multinational corporations adopt cultural integration measures by applying cultural means to alleviate the contradictions and conflicts arising from the interaction of different cultural groups within the transnational operation process. The purpose of crosscultural management is to solve the conflicts and contradictions in transnational management, so that different forms of culture can be understood, respected, coordinated and integrated to achieve the effective operation of multinational enterprises, and cultural conflict is the centre of cross-cultural management Task, but also the most important cross-border management of high efficiency.

\section{The source analysis of cultural differences in the cross- cultural management}

Each country, each nation in its long history of the development process, have accumulated a set of their own unique culture. There are about 1,500 cultures of the peoples and regions of the world, and because of the different economic and superstructure, the forms and methods of satisfying people's basic needs are different, resulting in a wide variety of cultures. These cultural differences are rooted in the following forms:

\subsection{Differences in thinking patterns and behaviour patterns}

The mode of thinking activity is formed by the influence of different cultural background, personal knowledge structure, social and working environment and habits. Different modes of thinking are bound to produce different patterns of behaviour. Such as the Chinese people used to image thinking, preference for integrated thinking; Europe and the United States are used to abstract thinking, preferences analysis of thinking. Chinese people's comprehensive thinking embodied in the whole to the part of Europe and the United States people's analytical thinking is reflected from the part to the whole. Differences between the Eastern and Western modes of thinking are often the causes of cross-cultural intercultural communication and management conflicts.

\subsection{The differences in values}

Traditional culture is the deep accumulation of national culture. Such as: the differences in values between Chinese and Western cultures mainly in the 
collectivism and individualism, power differences in two aspects. Chinese people overemphasize the collective, ignoring the role of individual ability in the collective, so that individual talent is difficult to give full play, which also hindered the collective force effect. Westerners are highly motivated by personal initiative and measure the value of life with personal success. Chinese culture has always been known for its humble and courteous fine traditions, while Western culture is characterized by individualism, with no face or personality.

\subsection{The language differences}

Language differences seriously affect communication. Because of the highcontext language used by high-implicit cultures (such as China and Japan), much of the information is conveyed through body language, context, context, and other countries may be difficult to understand in the mother tongue To find the corresponding words, so inevitably produce contradictions and conflicts, it is difficult to properly resolve. Some joint ventures eventually embarked on the disintegration of the road of no return have more or less has such a reason.

\section{The impact of cultural differences on transnational operations}

Enterprises engaged in transnational business, across borders, ethnic, natural also crossed the culture, is bound to face the cultural differences brought about by different cultures and cultural conflicts. Cross-cultural differences on the impact of cross-border business are multifaceted, mainly as follows:

\subsection{Cultural differences affect market choice}

Different understanding of a country's culture, will directly affect the multinational business strategy in the choice of the market. Some well-known international scholars have different views on this: marketing experts believe that the innovative tendencies between countries mainly depends on the cultural traditions between countries and new products into the market time; sociologists believe that the world's cultural sub- For the high background and low background two broad categories of cultural types. In the high background culture, the same text with the text, the same convention, so information is easy to spread. In the low background culture, there are many sub-cultures in the society, which are independent of each other. This information is neither easy to spread, not easy to accept, in the performance of new products for commercial innovation in the process of imitation are less.

\subsection{Cultural differences affect the provision of products and services}

Entrepreneurs must consider cultural differences in deciding what products and services to offer to foreign markets. For example, China's pure and noble, elegant and elegant lotus pattern, in Japan, said the festival was intended. California beef 
noodle only has one branch in Los Angeles, while in China there are 77 branches, very attractive to the Chinese public. Coca-Cola's international marketing strategy of victory, depending on its advertising production is suitable for national conditions, and now Coca-Cola has been deeply rooted in the hearts of Chinese consumers.

\subsection{Cultural differences affect market access methods}

In entering a new market, it is important to take into account international cultural differences and thus to determine the means to enter the market, which is a key factor in determining the trade-offs. For example, the media predators Murdoch's News Group in the Western market, in order to break through each other's cultural barriers and avoid host country people have a sense of resentment, the use of mergers and acquisitions, and voted to enter its various cultural life, received quite Good effect.

\section{The cross - cultural management strategy in cross - border business}

\subsection{Foster common corporate values and establish a unified value system}

Enterprise value refers to the enterprise in the pursuit of business success in the process of believing and respected the basic code of conduct, is the accumulation of long-term business activities and summary. In the multinational companies, from different cultural backgrounds of the management and employees have different corporate values. Employees are always full of pride in their own country's culture, and are puzzled or incongruous about cultures from other countries. Therefore, in multinational enterprises, the training of employees of corporate values, we must first eliminate the sense of racial superiority, respect and understanding of each other's culture, with an equal attitude to communicate, and on this basis to find two or more Cultural integration point, give full play to the advantages of both cultures in the enterprise to gradually establish a common values.

\subsection{Make cross-cultural training to achieve cultural empathy}

One of the most effective ways for companies to truly penetrate the host country's market, to successfully implement multinational operations, and to gain a deeper understanding of the local corporate culture is to conduct cross-cultural training. The practice of multinational companies shows that, through cross-cultural training, enterprises managers and employees can quickly understand the culture of the cooperating countries and greatly reduce the possibility of cultural conflicts. 


\subsection{Expand communication channels and establish cross-cultural enterprise management communication mechanism.}

The so-called cross-cultural communication refers to two or more with different cultural backgrounds of people or groups to express ideas, communication, exchange of feelings and the formation of interactive behaviour process. The essence of cross-cultural communication is mutual respect and understanding of culture. In order to solve the problem of cultural differences in transnational business, it is necessary to enhance the understanding between managers and employees from different cultural backgrounds and emphasize the importance of communication. Establish a good communication, expansion of communication channels, the use of easy to be accepted within the enterprise communication methods, the formation of a more open and inclusive communication environment, prompting employees out of self-enclosed social, work and life circle, free and harmonious within the enterprise to communicate and collaborate.

\section{Conclusion:}

Under the background of culture, managers and employees should combine the needs of different stages of development and the degree of cultural adaptation, integrate the common cultural values which belong to the enterprise, and help enterprises in transnational management In order to maximize the cultural differences to overcome the contradictions and conflicts, and then play the cultural diversity brought about by complementary advantages, and ultimately achieve the ultimate goal of transnational business.

\section{References}

[1] Bai Aizheng. Cultural Identity in Multinational Corporation Localization. Economist, 55(12), pp.68-70, 2011

[2] Bao Shenghua. On Cross - cultural Management of Enterprises. Management Science, 8 (5), pp.87- 91, 2013

[3] Tang Yanzhao, Lu Wei. Foreign Cross - cultural Management Research and Enlightenment. Management frontier, 12(10), pp. 18- 20, 2012

[4] Guo Xiangang. On Cross - cultural Management of Multinational Corporations. Economic Management, 9(6), pp.58- 61, 2011

[5] Chen Jianping, Xu Weijun. A Brief Analysis of Cross - cultural Communication and Management. Economy Forum 8(4), pp.85-87, 2014 